\title{
Mountain biodiversity and ecosystem functions: interplay between geology and contemporary environments
}

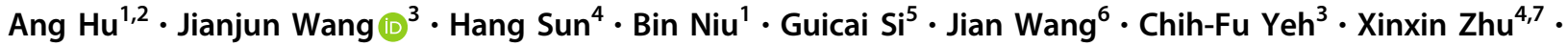

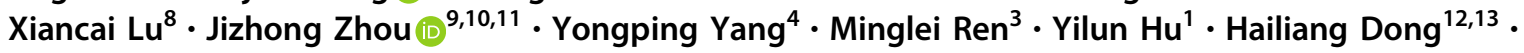 \\ Gengxin Zhang ${ }^{1}$
}

Received: 8 September 2019 / Revised: 25 November 2019 / Accepted: 16 December 2019 / Published online: 2 January 2020

(c) The Author(s) 2020. This article is published with open access

\begin{abstract}
Although biodiversity and ecosystem functions are strongly shaped by contemporary environments, such as climate and local biotic and abiotic attributes, relatively little is known about how they depend on long-term geological processes. Here, along a 3000-m elevational gradient with tectonic faults on the Tibetan Plateau (that is, Galongla Mountain in Medog County, China), we study the joint effects of geological and contemporary environments on biological communities, such as the diversity and community composition of plants and soil bacteria, and ecosystem functions. We find that these biological communities and ecosystem functions generally show consistent elevational breakpoints at 2000-2800 m, which coincide with Indus-Yalu suture zone fault and are similar to the elevational breakpoints of soil bacteria on another mountain range $1000 \mathrm{~km}$ away. Mean annual temperature, soil $\mathrm{pH}$ and moisture are the primary contemporary determinants of biodiversity and ecosystem functions, which support previous findings. However, compared with the models excluding geological processes, inclusion of geological effects, such as parent rock and weathering, increases 67.9 and $35.9 \%$ of the explained variations in plant and bacterial communities, respectively. Such inclusion increases $27.6 \%$ of the explained variations in ecosystem functions. The geological processes thus provide additional links to ecosystem properties, which are prominent but show divergent effects on biodiversity and ecosystem functions: parent rock and weathering exert considerable direct effects on biodiversity, whereas indirectly influence ecosystem functions via interactions with biodiversity and contemporary environments. Thus, the integration of geological processes with environmental gradients could enhance our understanding of biodiversity and, ultimately, ecosystem functioning across different climatic zones.
\end{abstract}

\section{Introduction}

It has long been the core of ecology for disentangling the mechanisms underlying temporospatial distributions of biodiversity, and further ecosystem functions [1-4]. Biodiversity is by no means the only, or even the primary, driver of ecosystem functions $[5,6]$. Both biodiversity and ecosystem functions have been known to be driven by common

These authors contributed equally: Ang Hu, Jianjun Wang

Supplementary information The online version of this article (https:// doi.org/10.1038/s41396-019-0574-x) contains supplementary material, which is available to authorized users.

Gengxin Zhang

zhangg@itpcas.ac.cn

Extended author information available on the last page of the article drivers of contemporary environments, such as climate and biotic and abiotic attributes [2, 4, 7, 8]. Biodiversity could be also shaped by long-term drivers, such as geological processes, which impart lasting legacies on contemporary environments ([1, 9, 10]). This is especially true for mountain regions, where a close link between geological processes and biological communities has been recently revealed by showing the effect of erosion and soil heterogeneity on biodiversity of terrestrial tetrapods [11]. However, geological processes have not yet been assessed for effects on microbial communities and ecosystem functions. Furthermore, the interactions between contemporary and geological processes have rarely been documented in regard to their influence on biological communities and ecosystem functions.

To better understand the underlying mechanisms, we propose a framework integrating biology and earth sciences by incorporating both contemporary environments 


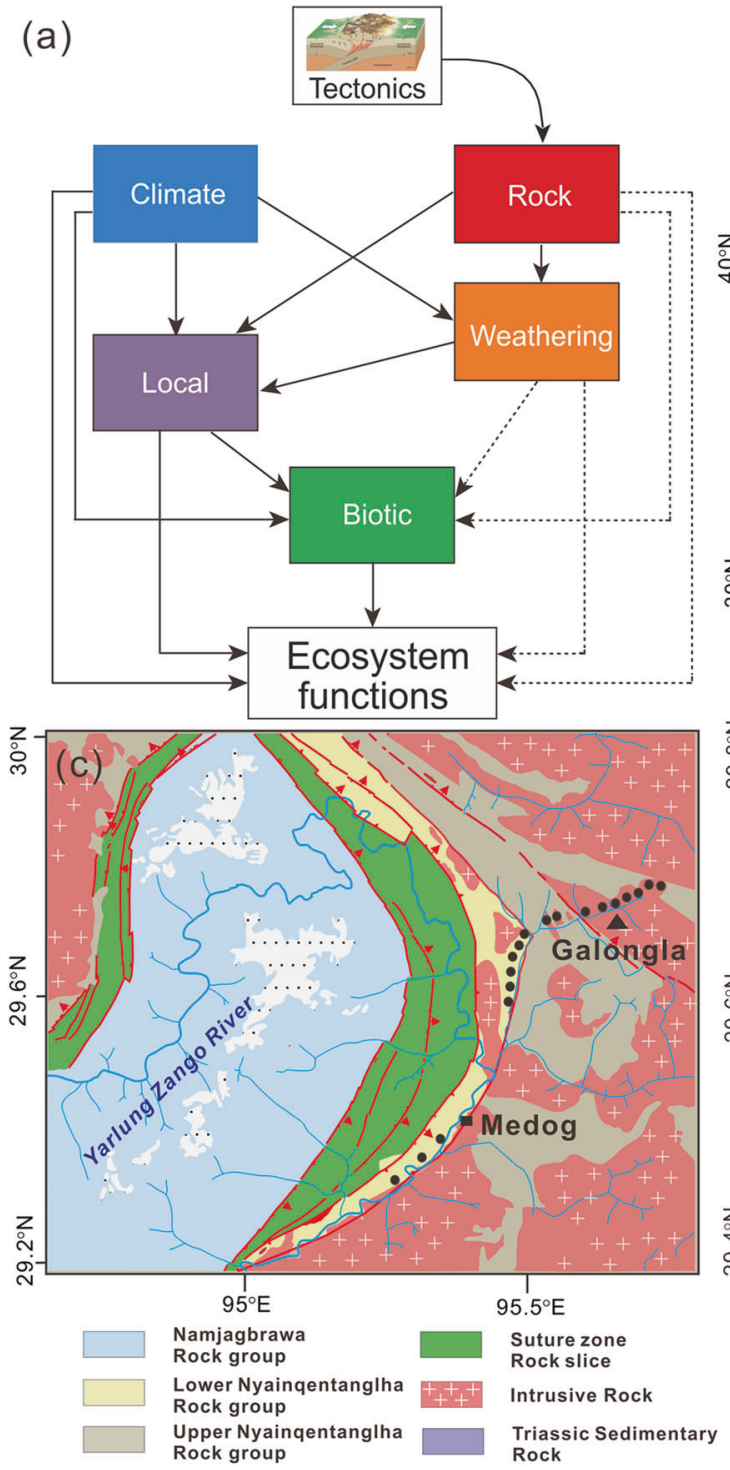

Fig. 1 Hypothesized mechanisms for biological communities and ecosystem functions, and sampling maps. a Conceptual model showing hypothesized relationships among contemporary environments (e.g., climate, local, and biotic), long-term geological (e.g., parent rock and weathering) processes and ecosystem functions. Solid arrows depict known causal relationships, whereas dashed arrows show the hypothesized but not explicitly documented relationships.

and long-term geological processes on mountainsides (Fig. 1a). Mountain ranges, created and affected by geological processes, have tectonic boundaries, such as sutures and faults [12], and show predictable trends in climatic and abiotic environmental factors with elevation, and thus show plant and animal zonation. For example, the Himalayan-Tibetan orogeny was developed by the collision of the Indo-Malaysia and Eastern-Asia tectonic plates [13, 14] and harbors dozens of major faults [12]. The resulting mountain ranges cover almost all major natural ecosystem types on Earth and are important in (b)
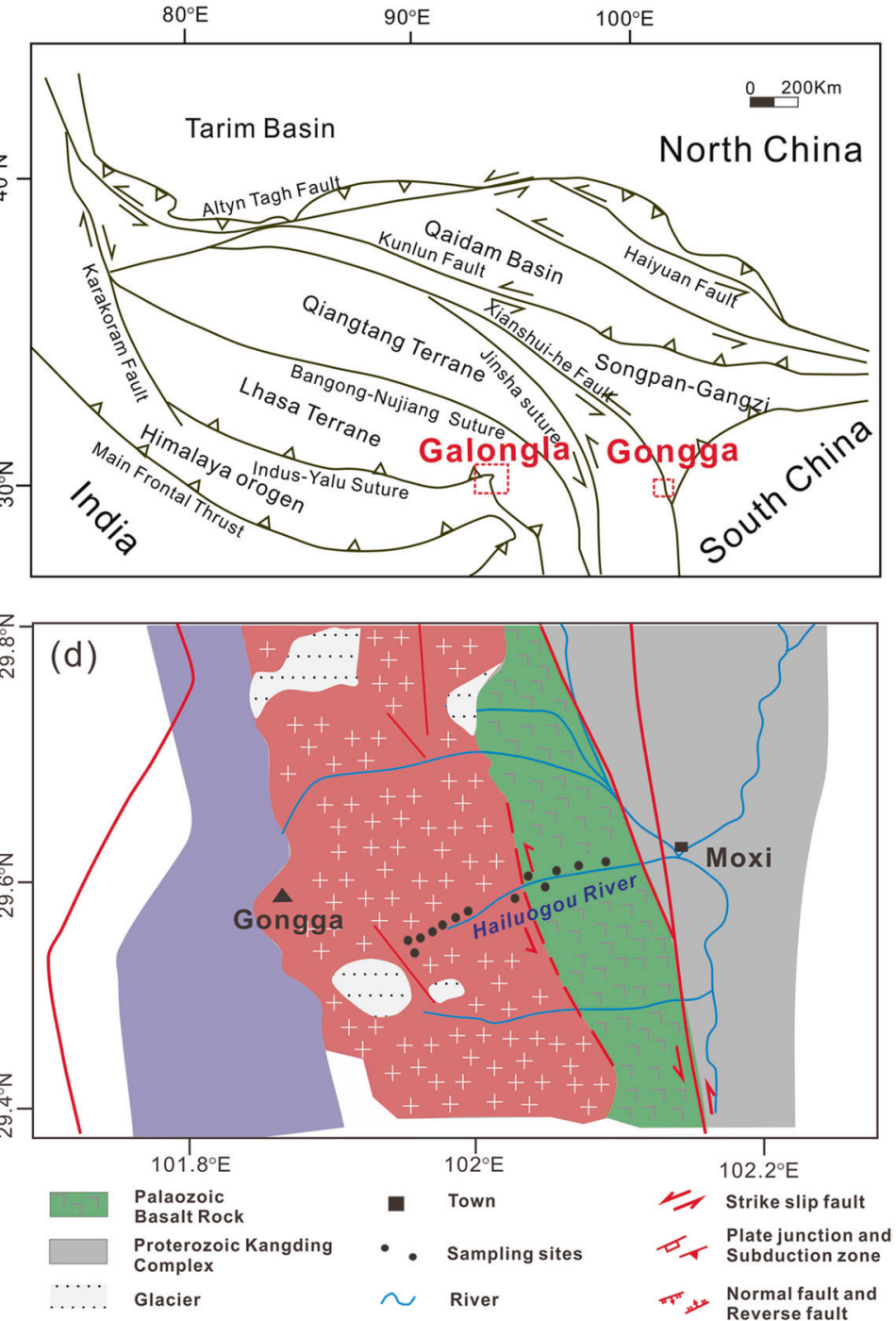

b Tectonic map of the Tibetan Plateau showing the locations of Galongla and Gongga mountains. c Sampling sites on Galongla Mountain in Medog, Tibet. This elevational gradient extends across the Indus-Yalu suture zone fault (red lines) bounded by the Himalaya and Gangdese terranes. $\mathbf{d}$ The sites sampled on Gongga Mountain by Li et al. [18]. The elevational gradient is intercepted by a secondary Xianshuihe fault (red lines).

maintaining biodiversity and ecosystem functions, such as South-East Tibet biodiversity hotspot [15]. Elevation gradients in mountain regions are invaluable as a natural laboratory for the empirical testing of the hypothesized framework (Fig. 1a) for biodiversity patterns $[16,17]$ and their links to ecosystem functions.

In this study, we addressed the question of how biodiversity and ecosystem functions vary along an elevational gradient, what are the main drivers for such elevational patterns (contemporary environments versus geological processes), and how geological processes directly and 
indirectly affect biodiversity and ecosystem functions. Along an elevational gradient of 700-3760 m on Galongla Mountain on the South-East Tibetan Plateau, we examined the biological communities and ecosystem functions for 180 plots at 18 sites covering multiple climatic and vegetation zonations from tropical monsoon rainforests to frigid shrub meadows (Fig. 1b, c). The selected elevational gradient crosses multiple faults with contrasting rock formations that result from the movements and collisions of the Himalaya and Gangdese terranes (Fig. 1b). We examined geological variables, such as soil parent rock and weathering conditions, and contemporary environments, such as climate, local, and biotic attributes (Fig. 1a, S1). For biotic attributes, we determined the relative abundance, diversity, and community composition of plants and bacteria. We further measured 38 ecosystem functions, which are categorized into functional groups including soil nutrients, plant biomass, microbial biomass, and carbon cycling and storage (Table S1), and we characterized three facets of ecosystem functioning: individual function, ecosystem multifunctionality (EMF) [6], and the composition of ecosystem functions. EMF is an integrated ecosystem function metric to indicate the simultaneous performance of multiple functions [6]. We finally tested the consistency in biodiversity elevational patterns by comparing our results to the reported bacterial communities of Gongga Mountain [18] on the South-East Tibetan Plateau (Fig. 1d). The framework regarding "Materials, Methods, and Aims" is shown in Fig. S2. We expected that the biodiversity of plants and microbes, and ecosystem functioning would be strongly affected by contemporary environments, such as soil $\mathrm{pH}$ and current climates. We further expected the long-term processes (that is, parent rock and weathering) would directly mediate the biodiversity and ecosystem functioning, but also show indirect influences via the interaction with contemporary environments. These hypothesized links for biological communities and ecosystem functions are shown in Fig. 1a.

\section{Materials and methods}

\section{Site description}

We examined a $3000-\mathrm{m}$ elevational gradient $\left(29^{\circ} 28^{\prime}-29^{\circ}\right.$ $75^{\prime} \mathrm{N}, 95^{\circ} 20^{\prime}-95^{\circ} 71^{\prime}$ E) on Galongla Mountain in Medog County, the lower reach of the Yalu Tsangpo River in South-East Tibetan Plateau, China (Figs. 1b, c). Galongla Mountain is a part of the Gangrigabu Mountain range, and the elevations go through the Indus-Yalu suture zone fault. This region was highly geologically dynamic as being in a strong tectogenetic area [19]. The Indus-Yalu suture is bounded by the Himalaya and Gangdese terranes, which are originally derived from the Indo-Malaysia and Eastern-Asia plates, respectively.

Along this elevational gradient, a full range of vegetation types is distributed. At the lowest elevation (below $1100 \mathrm{~m}$ ), there is the northernmost and highest-elevation tropical monsoon rain forest zone in the Northern Hemisphere. Toward high elevations, vegetation zones are the following: subtropical evergreen broadleaved forests $(1100-2000 \mathrm{~m}$ ), subtropical evergreen and semi-evergreen broadleaved forests (2000-2500 m), temperate mixed coniferous broadleaved forests $(2500-3000 \mathrm{~m})$, frigid-temperate coniferous forests (3000-3700 m), and frigid shrub meadows beyond $3700 \mathrm{~m}$.

\section{Vegetation survey and soil sampling}

In July-August of 2012, we performed vegetation surveys and soil sampling at 18 sites or elevations ranging from 700 to $3760 \mathrm{~m}$ across the six vertical vegetation zones. Each site was carefully selected based on soil formation and no glacial, river, and wind impacts were identified. For plant communities, we established ten plots of $10 \mathrm{~m} \times 10 \mathrm{~m}$ on each site for trees, and $5 \mathrm{~m} \times 5 \mathrm{~m}$ plots for shrubs. The identification level of plants varied from species to family, and we recorded virtual taxa (hereafter species) and the number of individuals of each species for the estimation of density, coverage, and height within each plot. Plant importance values were computed as the average of the relative density, coverage, and height. We categorized plants as trees (that is, fir, hardwood and softwood), shrubs, and herbs. Plant biomass for these plant types was estimated as follows [20-22]: (1) fir biomass $=(0.4642 V+47.4990) /$ 100; (2) hardwood biomass $=\left(0.6573 V^{\wedge} 1.0502\right) / 100$; (3) softwood biomass $=\left(2.1529 V^{\wedge} 0.6085\right) / 100$; (4) shrub biomass $=(0.0398 *$ height $* 100-0.3326) *$ coverage $/ 25$; and $(5)$ herb biomass $=(0.0175 *$ height $* 100-0.2888) *$ coverage. $V$ represents volume, and was calculated as $V=$ $100 *$ height $*$ coverage.

For soil samples, we randomly collected 25 soil cores from the upper $10 \mathrm{~cm}$ using a soil auger $(\Phi 5 \mathrm{~cm})$ from each plot, and then mixed them as one composite sample. Totally, there were ten composite soil samples for each site, and 180 samples for the whole elevational gradient. For each composite sample, $500 \mathrm{~g}$ of soils was sieved through a 2-mm mesh and then stored at $4{ }^{\circ} \mathrm{C}$ for physiochemical and enzyme activity analyses or at $-80^{\circ} \mathrm{C}$ for organic chemical and molecular analyses.

\section{Climate and soil physiochemical variables}

For each site, mean annual temperature was predicted with local meteorological stations using a linear model with latitude, longitude and elevation as explanatory variables. Mean annual precipitation was obtained based on the datasets from 
the Climate Hazards group InfraRed Precipitation with Stations (CHIRPS, http://chg.geog.ucsb.edu/data/chirps/) and local meteorological stations in the study area using leastsquares polynomial curve-fitting with elevation [23].

We measured soil physiochemical variables, namely, soil moisture, $\mathrm{pH}$, total nitrogen (TN), total phosphorus (TP), total organic carbon (TOC), water-soluble soil organic carbon (WSOC), water-soluble soil organic nitrogen (WSON), $\mathrm{NO}_{3}{ }^{-}-\mathrm{N}$, and $\mathrm{NH}_{4}{ }^{+}-\mathrm{N}$, according to previous literatures $[24,25]$.

\section{Geological variables}

The mineral components of soil parent rock, including quartz, plagioclase, K-feldspar, amphibole, muscovite, and chlorite, were identified. We used individual minerals to perform the principal component analysis (PCA, Fig. S3a), and the first two axes of PCA accounting for $61.4 \%$ of the total variance were used as explanatory variables representing the soil parent rock. Then, we measured metal elements including $\mathrm{Ca}, \mathrm{Fe}, \mathrm{Mg}, \mathrm{Al}, \mathrm{K}, \mathrm{Na}, \mathrm{Mn}$, and Ti. The first two axes of PCA of these metal elements explaining $80.3 \%$ of the variance (Fig. S3b) were used to indicate geochemical factors. We further computed several weathering indices, such as the chemical index of alteration (ClA) [26], and the $\mathrm{Ti} / \mathrm{Fe}, \mathrm{Ti} / \mathrm{Al}, \mathrm{Mg} / \mathrm{Al}$, and $\mathrm{Ca} / \mathrm{Al}$ ratios. The detailed measurements of mineral components and metal elements were described in Supplementary Information.

\section{Phospholipid fatty acids (PLFAs), glycerol dialkyl glycerol tetraether (GDGT), and soil enzyme activities}

To further estimate microbial composition and biomass, we analyzed PLFAs [27] and GDGTs [28]. The PLFAs were extracted and measured according to previous literature [29], and the identified PLFA peaks were further grouped into fungi, bacteria, actinomycetes, or protozoa according to their origins [27]. The GDGTs, including isoprenoid GDGTs (iGDGTs) and branched GDGTs (bGDGTs), were extracted and estimated as previously described [30]. The iGDGTs and bGDGTs were derived from Archaea and bacteria, respectively [31]. To determine the activity of soil enzymes, we measured $\beta$-glucosidase, amylase, invertase, phenol oxidase, and cellulase as previously described [32]. More details on the extraction and measurements of PLFAs, GDGTs, and soil enzymes could be found in Supplementary Information.

\section{Bacterial communities}

DNA was extracted based on $0.5 \mathrm{~g}$ of frozen soils using the FastDNA $^{\circledR}$ SPIN Kit for Soil (MP Biomedicals, USA) following the manufacturer's instructions. DNA quality was assessed with a NanoDrop ND-2000c UV-Vis spectrophotometer (Thermo Fisher Scientific, USA). PCR amplification of the 16S rRNA gene hypervariable region V4 was performed with the primers $515 \mathrm{~F}\left(5^{\prime}\right.$-GTGCCAGCMGC CGCGGTAA-3') and 806R (5'-GGACTACHVGGGTWT CTAAT $-3^{\prime}$ ) [33]. The $2 \times 250$ bp paired-end sequencing of the PCR amplicons was conducted on a MiSeq platform (Illumina, USA). Sequencing data were analyzed using an in-house Galaxy software platforms [34] (IEG sequence analysis pipeline, http://zhoulab5.rccc.ou.edu:8080), as described in details in Supplementary Methods and Table S2. To ensure that biodiversity estimates were not biased or confounded by variation in sampling intensity (Fig. S4), the bacterial communities were rarefied at 10,000 sequences for the following analyses. We welcome future studies to support our current findings obtained from rarefaction by applying other alternative approaches, such as the mixture model framework proposed by McMurdie and Holmes [35].

\section{Estimating biological communities}

We considered the plant and bacterial communities from three facets: relative abundance, diversity, and community composition. For plants, the relative abundance was calculated for different plant types (that is, tree, shrub, and herb) and each species present in 5-95\% of the samples. Species richness was estimated using the number of plant species for all plants and different plant types. Detrended correspondence analysis (DCA) [36] with default 26 segments (the same for the following analyses) was used to evaluate changes in the plant community across different vegetation zones or elevations. The plant community compositions were represented by the first two DCA axes for all plants and the different plant types. The analyses of species richness and DCA were performed using the R package vegan V2.4.6 [37].

For bacteria, we considered the relative abundance at the phylum level. OTUs were agglomerated at the phylum level and the relative abundance was calculated. Species richness was calculated using the number of OTUs for the whole bacterial community and their phyla. We also estimated the alternative metrics, such as Chao 1 [38] and phylogenetic diversity [39] and found they showed strong correlations with species richness $\left(R^{2}=0.97\right.$ and 0.96 , respectively). Thus, we used species richness in the following analyses. To represent the bacterial community compositions, we used the first two axes of DCA for the whole bacterial community and their phyla by using the total OTU table and the OTU table of each bacterial phylum, respectively. We selected 18 dominant bacterial phyla that were present in more than $80 \%$ of the samples by following previous 
references [40], and such additional analyses were used to support the findings obtained at the whole community level. We divided the Proteobacteria phylum into different classes (hereafter phyla) because of the high relative abundance and diversity of Proteobacteria and the different ecological functions of these classes.

To summarize biodiversity, we computed a single-index multidiversity (MD) as a synthetic measure [41] by using an approach of averaging standardized values of the species richness of plants and the whole bacterial community, and also the species richness of dominant bacterial phyla. We considered both the whole community and phylum levels because that bacterial phyla have greater phylogenetic or physiological diversity than those of animals and plants [42, 43], and could show distinct biogeographical patterns in biodiversity [40, 44].

\section{Estimating ecosystem functions}

Similar to plant and bacterial communities, we considered ecosystem functions from three facets, that is individual function, EMF, and the composition of ecosystem functions. We quantified 38 ecosystem functions categorized by five functional groups (Table S1): Plant biomass, microbial biomass, enzyme activities, the abundance of photosynthetic bacteria, and soil nutrients. The composition combination of these groups of ecosystem functions was referred as "composition of ecosystem functions". We included a large number of ecosystem variables to approximate as wide a range of different ecosystem functions as possible [45]. For plant biomass, we considered the biomass, the individual number, the mean height, and the coverage of trees (firs, hardwoods, and softwoods), shrubs, or herbs. For microbial biomass, we examined PLFA concentrations of the groups of bacteria, fungi, actinomycete, and protozoa, and the concentrations of bGDGT, iGDGT, GDGT-0, and Crenarchaeol. For photosynthetic bacteria, we included the relative abundances of Cyanobacteria, Rhodospirillales, Rhodocyclales, and Chlorobi. Finally, for soil nutrients, we considered the concentrations of TOC, TN, TP, WSOC, WSON, $\mathrm{NH}_{4}{ }^{+}-\mathrm{N}$, and $\mathrm{NO}_{3}{ }^{-}-\mathrm{N}$. Although we have included 38 ecosystem functions, some important functions are inevitably unmeasured, such as plant available phosphorus, carbon fixation, and nitrogen fixation, and future studies are encouraged to include more essential functions for comprehensive understanding of ecosystem functioning.

For EMF, we used an averaging approach, which aims to collapse multifunctionality into a single metric that estimates the average value of multiple functions observed in a given sample [2]. We calculated $Z$-scores for all variables evaluated, and the EMF was the average $Z$-score for all functions measured for each sample. EMF's for all functions and the above five functional groups were estimated. In addition, in order to evaluate the effects of the number of ecosystem functions on EMF, we calculated EMF using a series of all possible combinations from 10 to 38 functions with 1000 permutations. These EMF analyses were performed by using the R package multifunc V0.8.0 [46].

For the composition of ecosystem functions, we used the first two axis scores of DCA to assess the changes in the compositions of all ecosystem functions and also specific functional components, such as PLFAs, GDGTs, and enzyme activities, across the vegetation zones or elevations.

\section{Statistical analyses}

We used the following variables, including those related to contemporary environments and long-term geological processes, as explanatory variables. Contemporary processes included climate (i.e., temperature and precipitation), local (i.e., soil pH and moisture), and biotic attributes (i.e., the diversity and DCA of plants and bacteria). Geological variables included soil parent rock (i.e., quartz, plagioclase, K-feldspar, amphibole, muscovite, chlorite, and the first two PCA axes of minerals) and weathering conditions (i.e., CIA, $\mathrm{Ti} / \mathrm{Fe}, \mathrm{Ti} / \mathrm{Al}, \mathrm{Mg} / \mathrm{Al}$, and $\mathrm{Ca} / \mathrm{Al}$ ratios, and the first two PCA axes of metal elements). Detailed information about all explanatory variables is listed in Table S3. The response variables included biological communities (plants and bacteria) and ecosystem functions at the three abovementioned facets, and were analyzed for their elevational patterns and underlying drivers.

\section{(1) Elevational breakpoints of plants, bacteria, and ecosystem functions}

The relationships between elevations and explanatory or response variables were visualized with loess regression models. We further tested the breakpoints or abrupt changes for all explanatory and response variables along the elevational gradient using a piecewise linear regression analysis [47, 48] with the $\mathrm{R}$ package SiZer V0.1.5. We calculated bootstrapped confidence intervals for the breakpoint estimates [48]. The sampling sites along the elevational gradient on Galongla Mountain extend across the Indus-Yalu suture zone fault, which is located at $2293-2438 \mathrm{~m}$ (Fig. 1c). Therefore, we defined the elevational band for potential breakpoints within the range of $1800-3000 \mathrm{~m}$ in piecewise linear regressions. Furthermore, these breakpoint estimations of the compositions of plants, bacteria, and ecosystem functions were supported or explained by the following statistical analyses.

First, we visualized the separation among sites or elevations by the gradient of fitted contours, which implies a linear relationship between elevations and DCA ordinations 
of the biological communities and ecosystem functions. We further evaluated the significance of the compositional differences among the elevational zones by the permutational multivariate analysis of variance (PERMANOVA) method with pseudo-F statistic [49]. Heterogeneity of multivariate dispersion was not tested because PERMANOVA could allow rigorous meaningful analysis of even those having variables with extremely non-normal or overdispersed behavior [50]. This analysis was performed using the $\mathrm{R}$ package vegan V2.4.6 [37].

Second, we assessed the compositional changes and identified the important breakpoints across multiple species along the elevational gradient with gradient forest analysis [51]. In addition, we also estimated the standardized density of splits for bacteria across the taxonomic levels from genus to phylum where we agglomerated OTUs and thus the whole communities were considered at coarser taxonomic levels than species. These analyses were performed using $\mathrm{R}$ packages gradientForest V0.1.17 [51] and extendedForest V1.6.1 [52].

Third, we examined the Bray-Curtis dissimilarity [53] of biological communities or ecosystem functions between pairs of adjacent elevations to identify abrupt elevational compositional changes. The significance and magnitude of dissimilarity differences between adjacent sites were evaluated with PERMANOVA method with pseudo-F statistic. Within the elevation range of $1800-3000 \mathrm{~m}$, we considered the elevational breakpoint as the highest compositional turnover between adjacent elevations, which is defined as the highest pseudo-F statistic and dissimilarity value.

Fourth, we tested the regional consistency in elevational breakpoints by further examining bacterial communities from Gongga Mountain. This mountain is located on the South-East Tibetan Plateau and is over $1000 \mathrm{~km}$ away from Galongla Mountain. These two mountains have similar latitudes at $29-30^{\circ} \mathrm{N}$ and the sampling sites shared the elevation ranges from 1800 to $3800 \mathrm{~m}$. Gongga Mountain is a part of Hengduan Mountain range, and the elevations go through a secondary Xianshui-he fault with contrasting origins of rock formations (Fig. 1c). We collected the bacterial 16S rRNA sequences (NCBI Accession number PRJEB15866) from Li et al. [18], and processed the dataset, along with our data with the bioinformatic methods as described above. We examined the community variations between the two mountains from the following three perspectives: (1) We visualized the bacterial community compositions of the two mountains by DCA ordination with the elevational gradient of fitted contours. (2) We examined pairwise Bray-Curtis similarities between the bacterial communities at similar elevations of the two mountains to test the abrupt compositional changes along the elevational gradients. (3) We calculated the community Bray-Curtis similarities between each elevation of Gongga Mountain and all lower (or upper) elevations of Galongla Mountain and then examined the elevational patterns of these similarities. The upper and lower elevations were defined according to the elevational breakpoint identified from the piecewise linear regression analysis on the whole community compositions of plants or bacteria. The relationships between the community similarity and elevation were fitted and tested with a linear model and permutation tests in the $\mathrm{R}$ package lmPerm V. 2.1.0 [54].

\section{(2) Drivers of biological communities and ecosystem functions}

To evaluate the role or the relative importance of contemporary environments and long-term geological processes on biological communities or ecosystem functions, we performed various statistical methods, such as multimodel averaging [55], gradient forest [51], multiple regression, structural equation models (SEM) [56], variation partitioning (VPA) [57], and random forest analyses [58] (Fig. S2). In particular, the latter four analyses provided knowledge on whether the geological processes in the models provide significantly additional predictive strength for biological communities or ecosystem functions compared with those models with contemporary environments only. The analyses of multimodel averaging and SEM are described as below, while the others are detailed in Supplementary Information.

First, the multi-model approach could provide a quantitative measure of the relative importance of each explanatory variable $[55,59]$. Before doing the analyses, strongly correlated variables were dereplicated according to their correlation. Statistical dependence between the explanatory variables was assessed using Pearson correlation coefficients (two-tailed). One of the two variables was selected if their Pearson correlation is higher than 0.7. For plants and bacteria, we used the diversity and compositions of the whole plants and bacteria, and the relative abundance of species as response variables. For ecosystem functions, we used individual function, EMF and the composition of ecosystem functions as response variables. All variables were $Z$-score transformed to estimate the conditional modelaveraged parameter as standardized beta values, which enable us to compare the influences of different explanatory variables with different measurement units on biological communities and ecosystem functions.

We further explored the relationships of EMF and explanatory variables with the increasing number of functions, using multimodel averaging and Pearson correlation analyses. The relative influences of explanatory variables were quantified for climate, parent rock, weathering, local, and biotic variables, which was done by selecting variables with the highest absolute standardized beta values. The 
multi-model averaging analysis was performed by using the R package MuMIn V1.40.4 [60].

Second, SEM was used to test and quantify the interactive effects of contemporary environments and geological variables on biodiversity MD or ecosystem functions EMF. The approach begins by hypothesizing the underlying structure of causal pathways as shown in Fig. 1a. Then, the model is translated into regression equations, and these equations are evaluated against the data to support or refute the hypothesized paths. Through this process, SEM provides an understanding of direct and indirect effects of contemporary and geological processes on MD or EMF. To estimate the predictive strength of geological processes, we fit separate models for predictor variables including and excluding geological processes. ANOVA was used to test the significance of these two separate models. Before modeling, all variables in the SEMs were $Z$-score transformed to allow comparisons among multiple predictors and models. Similar to previous studies [61], we used composite variables to account for the collective effects of climate, parent rock, weathering, local, and biotic attributes, and the candidate observed indicators were shown in Table S3. The indicators for each composite were selected based on the multiple regressions of MD or EMF and the formula for calculating the composite variable for SEM models of MD and EMF were shown in Table S4. Based on all the hypothesized paths among composite variables (that is, full model; Fig. 1a), we examined all alternative models using AIC and overall model fit statistics [62]. We chose the final model that met the model fit statistics with the lowest AIC value. The detailed modeling fit indices for all alternative models were provided in Table S5. Adequate model fits were determined according to a non-significant $\chi^{2}$ test $(P>$ 0.05), low AIC value, high comparative fit index (CFI > $0.95)$ and low standardized root mean squared residual $($ SRMR $<0.05)$. We implemented SEMs using the $\mathrm{R}$ package lavaan V.0.5.23 [63], which provides multiplelatent variable models by utilizing path diagrams to explain the underlying relationships in the models.

\section{Results and discussion}

Generally, for the elevational gradients of biological communities and ecosystem functions, there were significant $(P<0.05)$ elevational breakpoints that mostly occurred at $2000-2800 \mathrm{~m}$ according to piecewise regression analyses [47, 48] (Fig. 2a-c, Table S6). In particular, the elevational variations for plant (Fig. 2g, S5a) and bacterial composition (Fig. 2h, S5b) showed significant breakpoints at 2400-2500 m. Both taxonomic groups showed the highest compositional turnover around these breakpoints, which was quantified by pairwise Bray-Curtis dissimilarity
(Fig. S6a, b) and gradient forest analyses [51] (Fig. 2d, e). This finding is supported by bacterial compositional turnover from the phylum to genus levels (Fig. S7a) and is more obvious toward higher taxonomic levels, such as class and order levels (Fig. 2e, S7a). The EMF of all 38 ecosystem functions, which is not likely to be affected by the number of functions considered (Fig. S8), had a breakpoint at 2293 m (Fig. 2c). The EMF for the functional groups, such as plant and microbial biomass and soil nutrients, showed significant breakpoints at $2200-2400 \mathrm{~m}$ (Fig. 2c, S9). Similar patterns were observed for elevational changes in the composition of ecosystem functions (Figs. 2c, 2i, S5c) and the highest compositional turnover occurred at 2600-2800 m (Fig. 2f, S6c). These breakpoints were particularly apparent for the compositions of some functional groups, such as phospholipid fatty acids [27], glycerol dialkyl glycerol tetraether [28], and extracellular enzymes essential for carbon cycling and storage, based on elevational variations in their compositions (Fig. S10, S5d-f) and the highest compositional turnover within the $1800-3000 \mathrm{~m}$ range (Fig. S6d-f).

These consistent elevational breakpoints in the community compositions of multiple taxonomic groups and ecosystem functions have less been reported in previous studies. The breakpoint elevations of bacterial communities are, however, unexpectedly consistent with those at 2600-2800 $\mathrm{m}$ for the diversity [18] and community composition (Fig. S11) of soil bacteria on Gongga Mountain (Fig. 1d), which is located over $1000 \mathrm{~km}$ east of the studied Galongla Mountain. Furthermore, the bacterial community similarity between pairwise sites with similar elevations of the two mountains was lowest at the breakpoint elevation of $2360 \mathrm{~m}$ (Fig. S11b). It should be noted that these two mountains are from two different mountain ranges, Gangrigabu and Hengduan Mountains, which have different orientations and mountain-building origins as a result of collision and extrusion of tectonic plates or terraces (Fig. 1b-d). Such breakpoint elevations are different from the corresponding treelines at $3600-3700 \mathrm{~m}$ on the two mountains and contrast with the reported breakpoints of soil bacteria occurring at the treelines on the other mountains [64]. Climate, such as temperature, is widely accepted to be the primary control for the treeline formation and maintenance of biological communities [65]. Our findings however indicate that biological communities and ecosystem functions may not be always dominantly influenced by climate, and further suggest their links to other new processes, such as the legacies of geological events. This argument is supported by two observations. First, the elevational bands that contain breakpoints surprisingly coincide with the locations of faults. Specifically, the IndusYalu suture zone fault [66] and the Xianshui-he fault [67] pass through the elevational bands of $2300-2500 \mathrm{~m}$ and 
Plants
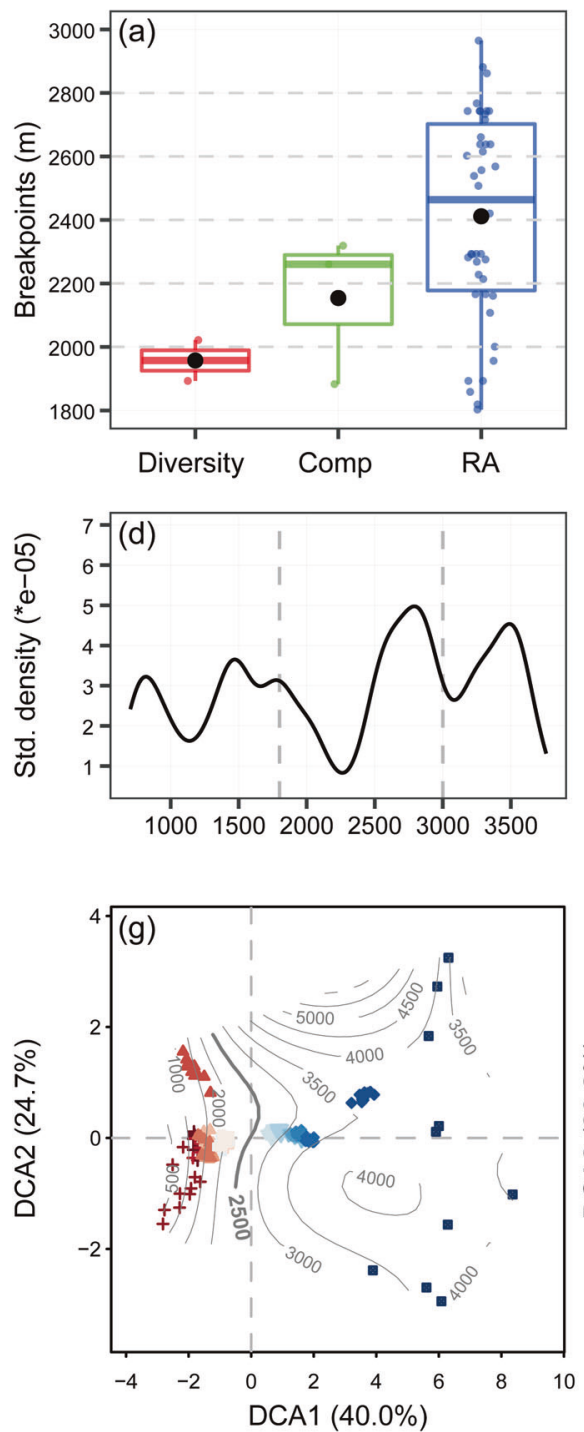

Bacteria
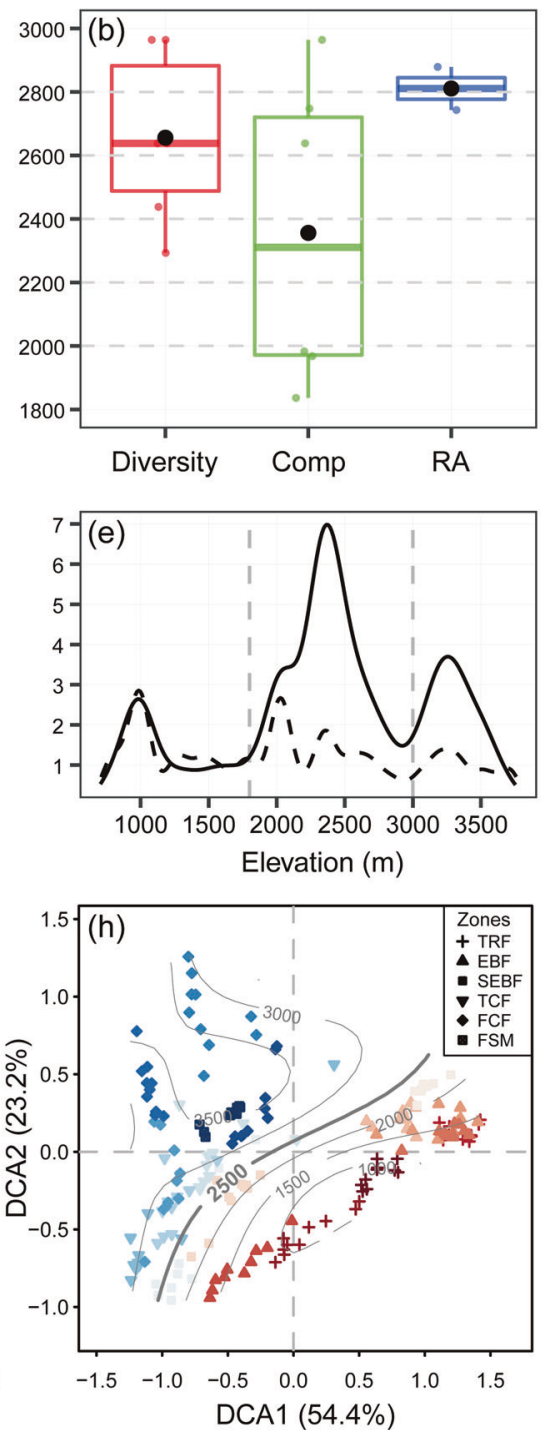

Functions
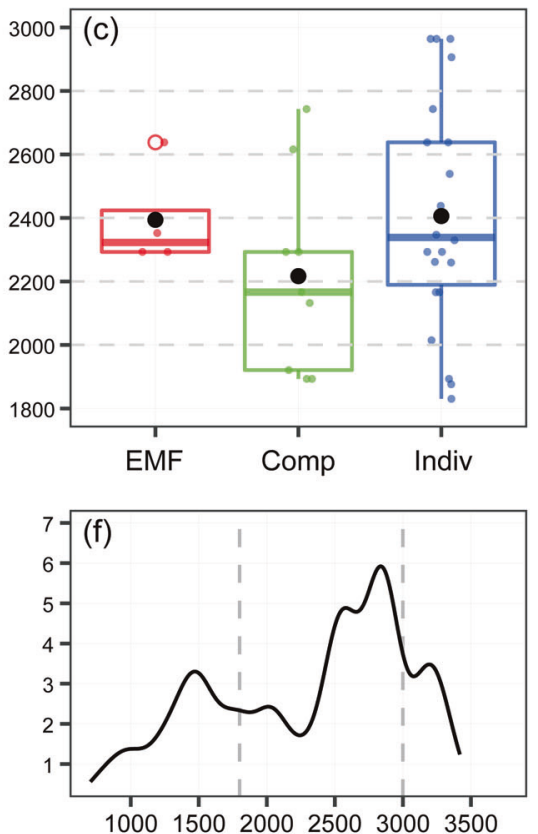

Fig. 2 Elevational patterns of plants, bacteria, and ecosystem functions. a-c The boxplots of elevational breakpoints (i.e., elevations with abrupt changes, colored dots) revealed by piecewise regression analyses [47, 48]. We considered three facets of plants: diversity and community composition (Comp) of whole plants and their types, and relative abundance (RA) of plant types and species. For bacteria, three facets are: diversity and community composition of whole bacteria and their phyla, and relative abundance of bacterial phyla. For ecosystem functions, three facets are: ecosystem multifunctionality (EMF) and composition of all ecosystem functions and their functional groups, and individual functions (Indiv). The average value of breakpoint elevations for each facet is shown with black point. The standardized density of splits showing where important changes in the abundance of multiple species or functions occur along the elevational gradient and indicating the compositional turnover. The standardized density of splits was determined by gradient forest analyses [51] for the species level of plants (d) and bacteria (dashed line, e), the class level of bacteria (solid line, e), or 38 ecosystem functions (f). The vertical

$2600-2800 \mathrm{~m}$ on the Galongla and Gongga Mountains, respectively. Most of chemical characteristics, including minerals, weathering indices, and soil properties, were dashed lines show the 1800-3000 $\mathrm{m}$ elevation ranges. One main peak within 1800-3000 m elevation ranges was more obvious at class than species level of bacteria. This is because broader taxonomic classification may balance the distribution uncertainty associated with finer taxonomic resolution and strengthen the phylogenetic conservatism [80]. Detrended correspondence analysis (DCA) plots of the composition of plants, bacteria, and ecosystem functions. DCA analyses were based on the species level of plants (g) and bacteria (h), and 38 ecosystem functions (i). The contours in gray indicate linear relationships between DCA ordination values and elevations. The compositional differences among pairwise elevations were analyzed to determine the highest compositional turnover as shown with bold lines (Fig. S5). Vegetation zones comprise tropical monsoon rain forest (TRF), subtropical evergreen broadleaved forest (EBF), subtropical evergreen and semi-evergreen broadleaved forest (SEBF), temperate mixed coniferous broadleaved forest (TCF), frigid-temperate coniferous forest (FCF), and frigid shrub meadows (FSM).

significantly $(P<0.05)$ different across the Indus-Yalu suture zone fault (results not shown). Second, the fault location on Galongla Mountain was supported by the 

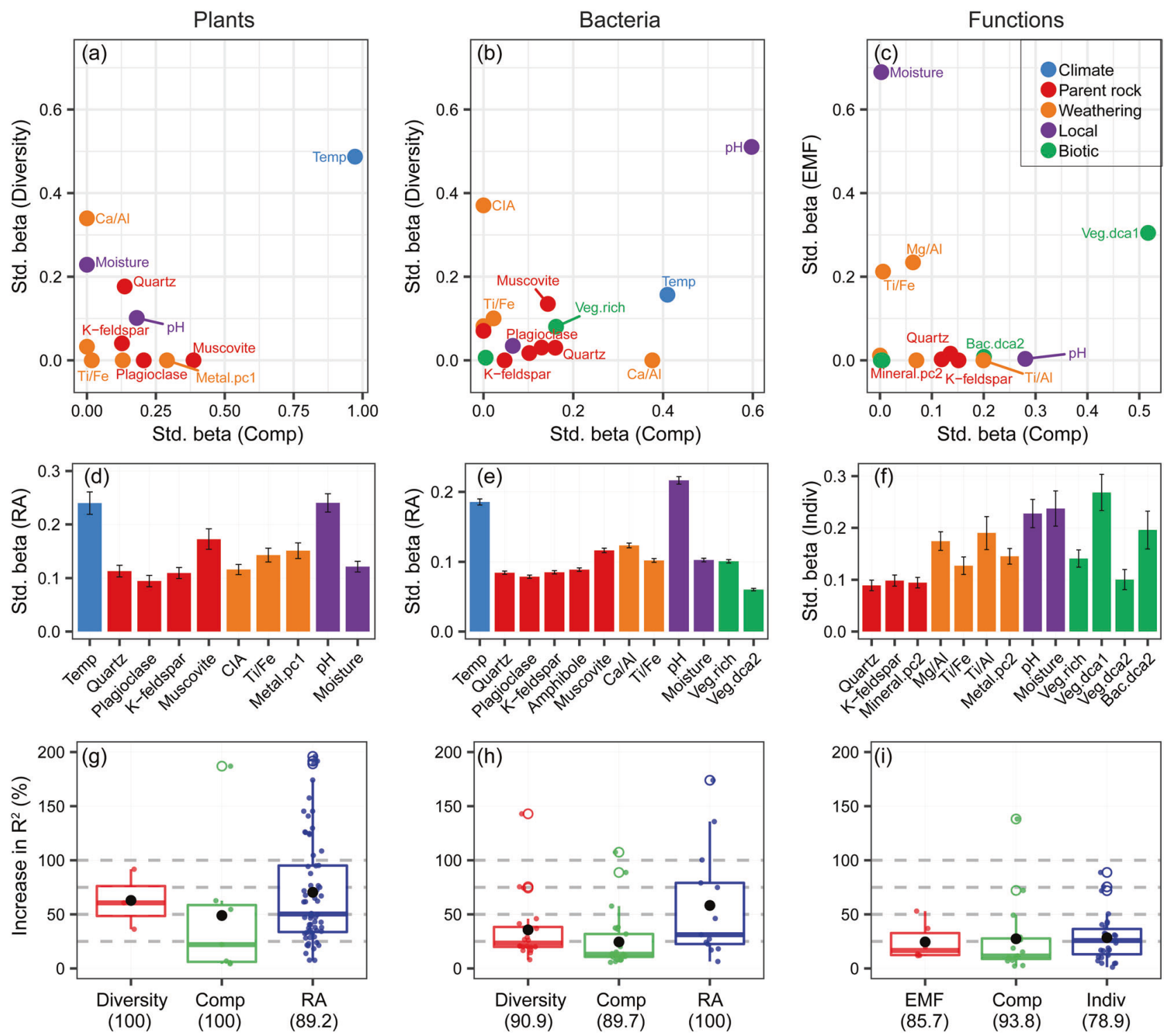

Fig. 3 Relative importance of contemporary and geological processes on plants, bacteria and ecosystem functions. First, the relative importance was quantified by the weighted averaging of parameter estimates over best-fitting models [59] by including the five groups of predictors (Fig. 1a): climate, parent rock, weathering, local, and biotic attributes. For plant $(\mathbf{a}, \mathbf{d})$ and bacterial $(\mathbf{b}, \mathbf{e})$ communities, we considered three facets: diversity (a, b), composition (Comp, a, b), and relative abundance (RA) of species (d, e). For ecosystem functions (c, f), the three facets are: ecosystem multifunctionality (EMF, c), the composition of ecosystem functions (c) and individual function (Indiv, f). Data in $\mathbf{d}-\mathbf{f}$ are presented as the means \pm s.e. Moreover, compared with the models of contemporary variables, we quantified the improvements in the explained variances by further including

elevational profile of the geological variables, such as the parent rock and weathering conditions, which showed breakpoints at $\sim 2400 \mathrm{~m}$ on average (Fig. S12).

Further statistical analyses to explore the key drivers of biological community and ecosystem functions reveal that both short- and long-term processes showed profound geological variables based on stepwise multiple regressions and Akaike's information criterion [81]. Relative to those in the models of contemporary variables, the improvements in the explained variances by including geological processes were shown as the percent increases in the model $R^{2}$ on the three facets of plant $(\mathbf{g})$ and bacterial (h) communities and ecosystem functions (i). The significance in model $R^{2}$ increase was determined with ANOVA between the models including and excluding geological variables. The values in parentheses indicate the percentage of significant $R^{2}$ increases among all possible models of contemporary variables for each facet. Black points in the boxplots are the mean values for each facet. The response variables were the same variables at three facets of plants, bacteria, and ecosystem functions as mentioned in Fig. 2a-c.

influences, including climate, parent rock, weathering, local, and biotic variables (Fig. 3, S7b, S13-S19). Among contemporary variables, mean annual temperature and soil $\mathrm{pH}$ had the strongest effects on the plant and bacterial communities, respectively (Fig. 3a, b, d, e). Ecosystem functions were most strongly affected by soil moisture, 
Fig. 4 Structural equation models of biodiversity and ecosystem functions. The biodiversity and ecosystem functions are quantified with single-index multidiversity (MD) and ecosystem multifunctionality (EMF), respectively. Best-fitting models illustrate the effects of predictor variables on MD $(\mathbf{a}, \mathbf{b})$ or EMF $(\mathbf{c}, \mathbf{d})$ by excluding $(\mathbf{a}, \mathbf{c})$ or including $(\mathbf{b}, \mathbf{d})$ geological variables. $R^{2}$ denotes the proportion of variance explained for endogenous variables. Gray and black arrows indicate statistically non-significant and significant $(* * * P<0.001, * * P<$ $0.01, * P<0.05)$ relationships, respectively. Arrow widths and accompanying numbers are the relative effects (that is, standardized path coefficients) of modeled relationships. Composite and observed variables are indicated in ovals and rectangles, respectively.

More details on the model fit are summarized in Table S5. (a)

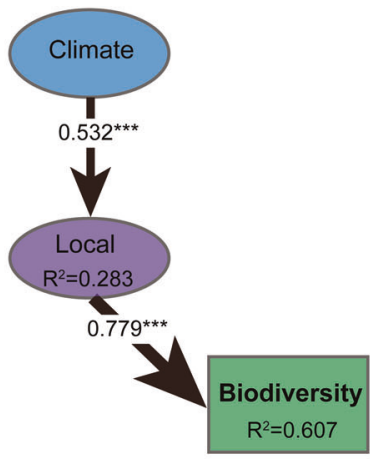

(c)

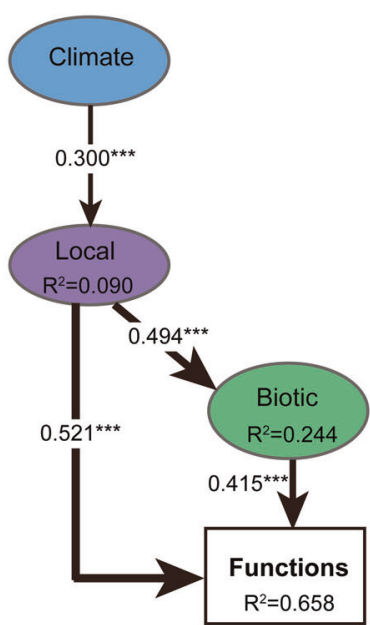

(b)

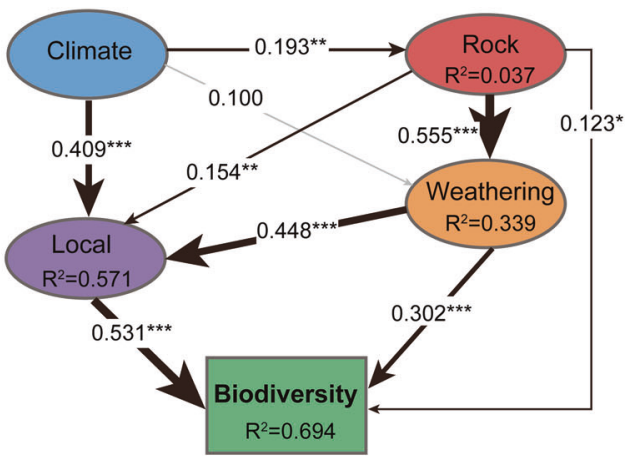

(d)

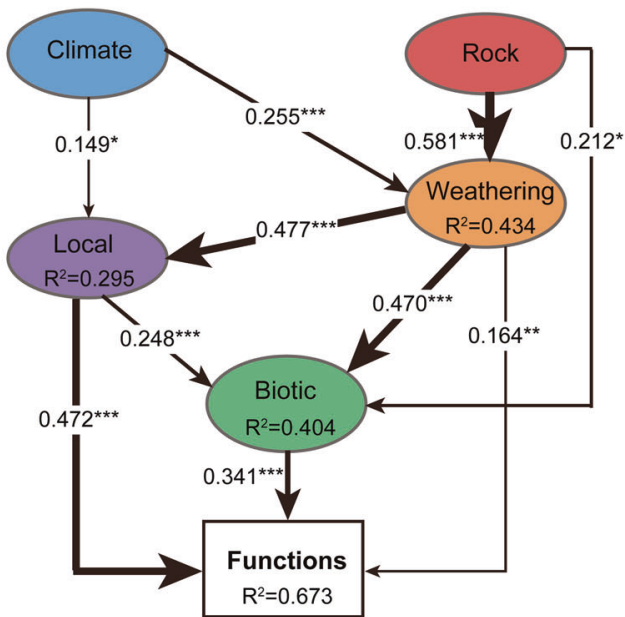

followed by plant communities (Fig. 3c). These findings support previous reports showing the important roles of contemporary environments, such as climate and local abiotic variables, in controlling global biodiversity $[4,11,68-72]$ and the roles of local abiotic variables and biodiversity in regulating ecosystem functioning [2, 73-75].

Furthermore, geological processes were found to be important as well in not only the plant and bacterial communities, but also ecosystem functions. For instance, bacteria were strongly correlated with weathering indices, that is, the chemical index of alteration [26] and the $\mathrm{Ca} / \mathrm{Al}$ ratio, when we considered the three facets of bacteria: the diversity and community compositions of total bacteria (Fig. 3b) and their phyla (Fig. S17), and the relative abundance of species (Fig. 3e). These facets of plants were significantly $(P<0.05)$ correlated with the $\mathrm{Ca} / \mathrm{Al}$ ratio, the geochemical composition, and primary minerals, such as muscovite, plagioclase, and quartz (Fig. 3a, d). EMF and the composition of ecosystem functions were also influenced by plant communities, as well as by weathering indices, such as $\mathrm{Mg}$ / $\mathrm{Al}$ and $\mathrm{Ti} / \mathrm{Fe}$ ratios (Fig. 3c, f). Furthermore, for the three facets of plant and bacterial communities and ecosystem functions, we found improvements in the explained variances in the models by including geological processes, of 67.9 and $35.9 \%$ on average for plant and bacterial communities, respectively, and of $27.6 \%$ on average for ecosystem functions, relative to those in the models excluding geological processes (Fig. $3 \mathrm{~g}-\mathrm{i}$ ). Thus, these findings suggest biological communities or ecosystem functions are driven by common mechanisms, that is contemporary environments and the new driver as long-term geological processes.

However, the interactive effect of the contemporary environments and long-term geological processes remains poorly understood. We thus applied SEMs [56] to statistically synthesize their hypothesized relationships (Fig. 1a). To summarize biodiversity, we computed a single-index MD parameter as a synthetic measure [41] by including the species richness of plant and whole bacterial community, and also the species richness of bacterial phyla. When all possible links among these two processes and ecosystem properties were considered (Fig. 1a), geological variables were retained in the final best-fitting SEMs and were revealed to improve the predictive power of the MD and EMF indices (Fig. 4, S20, Tables S5, S7, S8).

Furthermore, our SEMs showed that geological processes had divergent effects on MD and EMF due to the differences in their influence strength and directions. First, geological processes had a greater effect on MD than they did on EMF-after including geological variables, the 
explained variations of the MD and EMF models were improved by $8.7 \%$ and $1.5 \%$, respectively, but only the improvement of the MD model was significant $(P<0.001$, ANOVA) (Fig. 4a, b). Such divergent effects on MD and EMF are probably because biodiversity is functionally redundant [76, 77], so that the changes in MD do not necessarily alter EMF. Second, geological variables showed direct effects on MD, and mainly indirect influences on EMF via the interactions with biodiversity and contemporary abiotic environments. Specifically, geological factors, such as parent rock compositions, had strong correlations $(R>0.55, P=0)$ with weathering and showed total indirect effects of 0.38 and 0.34 on MD and EMF, respectively (Fig. 4b, d, Table S9). Weathering had significant direct effects on both MD $(R=0.30, P=0)$ and EMF $(R=0.16, P=0.008)$ and a strong indirect effect of 0.43 on EMF via local and biotic variables $(R>0.47, P=0$; Fig. 4b, d). Such divergent effects of geological processes were further statistically supported by variation partitioning analyses [57] (Fig. S21) and random forest analyses [58] (Fig. S22). For instance, the geological variables alone explained $10.0 \%$ and $1.0 \%$ of the variation in $\mathrm{MD}$ and EMF, respectively (Fig. S21), and improved the predictive power of MD and EMF by $4.3 \%$ and $3.9 \%$, respectively (Fig. S22). Thus, beyond those known from previous studies [2, 3, 11], our findings reveal additional links between geological processes relevant to tectonic dynamics and biological community or ecosystem functions, as previous studies of ecosystem functions have been largely concerned with effects of contemporary biotic and abiotic factors.

Because geological processes related to tectonic plate collision and faults are important on the Tibetan Plateau and in other biodiversity hotspots in mountain regions, our findings have several substantial implications regarding the effects of geological processes on biodiversity and ecosystem functions.

Firstly, our findings highlight the need to integrate data relating to the long-term geological history when making current inferences and future predictions of biodiversity or ecosystem functioning. This study, for the first time, include geological processes to quantify the relative contributions of past geological events on microbial communities and ecosystem functions. Our findings indicate that past geological processes leave a strong signature on the current distributional patterns of biodiversity and overall ecosystem functioning. Specifically, both parent rock and weathering had an indirect influence on ecosystem functions, whereas weathering had a considerable direct effect on biodiversity. Thus, our experimental strategy of explicitly considering geological events could be adopted, as it may facilitate the possibility of identifying and strengthening of the effects of geological processes on the biodiversity and ecosystem functioning.
Secondly, it is possible that elevational breakpoints of biodiversity may be observed in other geological regions with tectonic faults, and that biological communities could serve as indicators of past geological events, such as the formation of terrace boundaries or faults. This is because the consistent elevational breakpoints on the Galongla and Gongga Mountains are largely affected by faults attributed to past geological processes, even though these geological influences are from two different mountain ranges on the South-East Tibetan Plateau. The consistency in breakpoints on the two mountains indicates that the distributional patterns of biodiversity in other regions on the Tibetan Plateau or even around the world might show abrupt changes in similar and predictable ways across faults or even terrace boundaries. However, we should note that this implication of biological indicators was speculated based on two mountains, and current findings need further supports from other mountains, regions and continents.

Finally, further studies are encouraged to study the legacies of past geological events on biological communities and ecosystem functions, involving sampling along multiple elevational transects across faults and considering further more taxonomic groups with fine-resolution analytical approaches. For example, the studies in fungi [4] and animals [11, 78] or in multiple regions with similar geological processes, such as plate collision and tectonic faults, would be required to confirm the generality of our conclusions regarding the new links between long-term geological processes and biodiversity or ecosystem functioning. Furthermore, future studies are encouraged to include other drivers important for observed biogeography of plants and animals, such as seasonality, climate zones and geographical regions, at multiple time points in sampling strategy for comprehensive conclusions. A population ecology approach could be further applied to improve the methodology by evaluating genome legacies from a biological evolutionary perspective [79].

\section{Data availability}

The 16S rRNA sequences were deposited in NCBI Short Read Archive under accession number PRJNA556333. Other raw data were uploaded to the Dryad repository (https://doi.org/10.5061/dryad.fxpnvx0nb). Scripts for statistical analyses are available from the corresponding author upon reasonable request.

Acknowledgements This study was supported by National Natural Science Foundation of China (41871066, 41701084, 91851117, 41425009, 41775161, 41871048), the Second Tibetan Plateau Scientific Expedition and Research Program (STEP, Grant No. 2019QZKK0503), the Strategic Priority Research Program (A) of the 
Chinese Academy of Sciences (XDA20050101), and the Key Research Program of Frontier Sciences of the Chinese Academy of Sciences (QYZDBSSW-DQC043). We thank Xiangzhen Li for sharing sequence data of Gongga Mountain. We also thank Southeast Tibet Observation and Research Station for the Alpine Environment, Chinese Academy of Sciences (SETORS) for field sampling.

Author contributions GZ, JJW, HS, JZ, and YY conceived the idea. GS, JW, and XZ collected the samples. XL provided physiochemical data. CY and MR provided sequence data. AH and JJW performed data analyses. AH wrote the first draft of the manuscript. AH, JJW, and GZ finished the manuscript with contributions from all authors. All authors contributed to the intellectual development of this study.

\section{Compliance with ethical standards}

Conflict of interest The authors declare that they have no conflict of interest.

Publisher's note Springer Nature remains neutral with regard to jurisdictional claims in published maps and institutional affiliations.

Open Access This article is licensed under a Creative Commons Attribution 4.0 International License, which permits use, sharing, adaptation, distribution and reproduction in any medium or format, as long as you give appropriate credit to the original author(s) and the source, provide a link to the Creative Commons license, and indicate if changes were made. The images or other third party material in this article are included in the article's Creative Commons license, unless indicated otherwise in a credit line to the material. If material is not included in the article's Creative Commons license and your intended use is not permitted by statutory regulation or exceeds the permitted use, you will need to obtain permission directly from the copyright holder. To view a copy of this license, visit http://creativecommons. org/licenses/by/4.0/.

\section{References}

1. Jimenez-Alfaro B, Girardello M, Chytry M, Svenning JC, Willner W, Gegout JC, et al. History and environment shape species pools and community diversity in European beech forests. Nat Ecol Evol. 2018;2:483-90.

2. Maestre FT, Quero JL, Gotelli NJ, Escudero A, Ochoa V, Delgado-Baquerizo $\mathrm{M}$, et al. Plant species richness and ecosystem multifunctionality in global drylands. Science. 2012;335: 214-18.

3. Peters MK, Hemp A, Appelhans T, Becker JN, Behler C, Classen A, et al. Climate-land-use interactions shape tropical mountain biodiversity and ecosystem functions. Nature. 2019;568:88-92.

4. Tedersoo L, Bahram M, Põlme S, Kõljalg U, Yorou NS, Wijesundera R, et al. Global diversity and geography of soil fungi. Science. 2014;346:1256688

5. Giling DP, Beaumelle L, Phillips HRP, Cesarz S, Eisenhauer N, Ferlian O, et al. A niche for ecosystem multifunctionality in global change research. Glob Chang Biol. 2018;25:763-74.

6. Manning P, van der Plas F, Soliveres S, Allan E, Maestre FT, Mace G, et al. Redefining ecosystem multifunctionality. Nat Ecol Evol. 2018;2:427-36.

7. Grytnesn J-A, McCain CM. Elevational trends in biodiversity. Encyclopedia of Biodiversity. 2007;1-8.

8. Partel M, Bennett JA, Zobel M. Macroecology of biodiversity: disentangling local and regional effects. New Phytol. 2016; 211:404-10.
9. Martiny JB, Bohannan BJ, Brown JH, Colwell RK, Fuhrman JA, Green JL, et al. Microbial biogeography: putting microorganisms on the map. Nat Rev Microbiol. 2006;4:102-12.

10. Vass M, S. L. The legacy of the past: effects of historical processes on microbial metacommunities. Aquat Micro Ecol. 2017;79:13-9.

11. Antonelli A, Kissling WD, Flantua SGA, Bermúdez MA, Mulch A, Muellner-Riehl AN, et al. Geological and climatic influences on mountain biodiversity. Nat Geosci. 2018;11:718-25.

12. Yao H. Lithospheric structure and deformation in SE Tibet revealed by ambient noise and earthquake surface wave tomography: recent advances and perspectives. Earthq Sci. 2012;25:371-83.

13. Xu Z, Yang J, Li W, Li H, Cai Z, Yan Z, et al. Paleo-Tethys system and accretionary orogen in the Tibet Plateau. Acta Pet Sin. 2013;29:1847-60.

14. Yin A, Harrison TM. Geologic evolution of the HimalayanTibetan Orogen. Annu Rev Earth Planet Sci. 2000;28:211-80.

15. Myers N, Mittermeier RA, Mittermeier CG, da Fonseca GAB, Kent J. Biodiversity hotspots for conservation priorities. Nature. 2000;403:853-8.

16. Lomolino MV. Elevation gradients of species-density: historical and prospective views. Glob Ecol Biogeogr. 2001;10:3-13.

17. Sanders NJ, Rahbek C. The patterns and causes of elevational diversity gradients. Ecography. 2012;35:1-3.

18. Li J, Shen Z, Li C, Kou Y, Wang Y, Tu B, et al. Stair-step pattern of soil bacterial diversity mainly driven by $\mathrm{pH}$ and vegetation types along the elevational gradients of Gongga Mountain, China. Front Microbiol. 2018;9:569.

19. Peng B. Preliminary discussion on the vertical zonation in the Mt. Namjagbarwa region. Mt Res. 1984;2:182-9.

20. Fan W-Y, Zhang H-Y, Yu Y, Mao X-G, Yang J-M. Comparison of three models of forest biomass estimation. Chin J Plant Ecol. 2011;35:402-10.

21. Fu D, Song Q, Li D. Analysis of forest vegetation biomass and carbon storage in Motuo County of Tibet. Hunan For Sci Technol. 2015;42:67-72.

22. Zeng H, Liu Q, Feng Z, Ma Z, Hu L. Estimation models of understory shrub biomass and their applications in red soil hilly region. Chin J Appl Ecol. 2007;18:2185-90.

23. Knight RE. Least-squares polynomial curve-fitting utilizing orthogonal polynomials. Master of Science thesis, Texas Technological College, 1966.

24. $\mathrm{Hu} \mathrm{A}, \mathrm{Lu} \mathrm{Y}$. The differential effects of ammonium and nitrate on methanotrophs in rice field soil. Soil Biol Biochem. 2015; 85:31-8.

25. Shi Y, Li Y, Xiang X, Sun R, Yang T, He D, et al. Spatial scale affects the relative role of stochasticity versus determinism in soil bacterial communities in wheat fields across the North China Plain. Microbiome. 2018;6:27.

26. Nesbitt HW, Young GM. Early proterozoic climates and plate motions inferred from major element chemistry of lutites. Nature. 1982;299:715-7.

27. Hill GT, Mitkowski NA, Aldrich-Wolfe L, Emele LR, Jurkonie $\mathrm{DD}$, Ficke A, et al. Methods for assessing the composition and diversity of soil microbial communities. Appl Soil Ecol. 2000; $15: 25-36$

28. Schouten S, Hopmans EC, Sinninghe Damsté JS. The organic geochemistry of glycerol dialkyl glycerol tetraether lipids: a review. Org Geochem. 2013;54:19-61.

29. Frostegård A, Bååth $\mathrm{E}$. The use of phospholipid fatty acid analysis to estimate bacterial and fungal biomass in soil. Biol Fert Soils. 1996;22:59-65.

30. Yang H, Pancost RD, Tang C, Ding W, Dang X, Xie S. Distributions of isoprenoid and branched glycerol dialkanol diethers 
in Chinese surface soils and a loess-paleosol sequence: Implications for the degradation of tetraether lipids. Org Geochem. 2014;66:70-9.

31. Weijers JWH, Schouten S, Hopmans EC, Geenevasen JAJ, David ORP, Coleman JM, et al. Membrane lipids of mesophilic anaerobic bacteria thriving in peats have typical archaeal traits. Environ Microbiol. 2006;8:648-57.

32. Guan Y. Soil enzyme and methodology. Beijing: Agricultural press; 1986.

33. Caporaso JG, Lauber CL, Walters WA, Berg-Lyons D, Lozupone CA, Turnbaugh PJ, et al. Global patterns of $16 \mathrm{~S}$ rRNA diversity at a depth of millions of sequences per sample. Proc Natl Acad Sci USA. 2011;108:4516-22.

34. Giardine B, Riemer C, Hardison RC, Burhans R, Elnitski L, Shah $\mathrm{P}$, et al. Galaxy: a platform for interactive large-scale genome analysis. Genome Res. 2005;15:1451-5.

35. McMurdie PJ, Holmes S. Waste not, want not: why rarefying microbiome data is inadmissible. PLoS Comput Biol. 2014;10: e1003531.

36. Legendre P, Legendre L. Numerical ecology. Oxford, U.K.: Elsevier Scientific; 1998.

37. Oksanen J, Blanchet FG, Kindt R, Legendre P, Minchin P, O'Hara RB et al. vegan: Community Ecology Package. CRAN R package. 2017. https://cran.r-project.org/web/packages/vegan.

38. Chao A. Non-parametric estimation of the classes in a population. Scand J Stat. 1984;11:265-70.

39. Faith DP. Conservation evaluation and phylogenetic diversity. Biol Conserv. 1992;61:1-10.

40. Yeh CF, Soininen J, Teittinen A, Wang J. Elevational patterns and hierarchical determinants of biodiversity across microbial taxonomic scales. Mol Ecol. 2018;28:86-99.

41. Allan E, Bossdorf O, Dormann CF, Prati D, Gossner MM, Tscharntke $\mathrm{T}$, et al. Interannual variation in land-use intensity enhances grassland multidiversity. Proc Natl Acad Sci USA. 2014;111:308-13.

42. Giovannoni SJ, Stingl U. Molecular diversity and ecology of microbial plankton. Nature. 2005;437:343-8.

43. Prosser JI, Bohannan BJM, Curtis TP, Ellis RJ, Firestone MK, Freckleton RP, et al. The role of ecological theory in microbial ecology. Nat Rev Microbiol. 2007;5:384-92.

44. Fierer N, Bradford MA, Jackson RB. Toward an ecological classification of soil bacteria. Ecology. 2007;88:1354-64.

45. Meyer ST, Ptacnik R, Hillebrand H, Bessler H, Buchmann N, Ebeling A, et al. Biodiversity-multifunctionality relationships depend on identity and number of measured functions. Nat Ecol Evol. 2018;2:44-9.

46. Byrnes JEK, Gamfeldt L, Isbell F, Lefcheck JS, Griffin JN, Hector A, et al. Investigating the relationship between biodiversity and ecosystem multifunctionality: challenges and solutions. Methods Ecol Evol. 2014;5:111-24.

47. Chiu G, Lockhart R, Routledge R. Bent-cable regression theory and applications. J Am Stat Assoc. 2006;101:542-53.

48. Toms JD, Lesperance ML. Piecewise regression: a tool for identifying ecological thresholds. Ecology. 2003;84:2034-41.

49. Anderson MJ. A new method for non-parametric multivariate analysis of variance. Austral Ecol. 2001;26:32-46.

50. Anderson MJ. Permutational Multivariate Analysis of Variance (PERMANOVA). Wiley Stats Ref: Statistics Reference Online. 2017;1-15.

51. Ellis N, Smith SJ, Pitcher CR. Gradient forests: calculating importance gradients on physical predictors. Ecology. 2012;93: 156-68.

52. Liaw A, Wiener M. Classification and regression by random forest. R News. 2002;2:18-22.

53. Bray JR, Curtis JT. An ordination of upland forest communities of Southern Wisconsin. Ecol Monogr. 1957;27:325-49.
54. Wheeler B, Torchiano M. lmPerm: permutation tests for linear models. 2016.

55. Burnham KP, Anderson DR, Huyvaert KP. AIC model selection and multimodel inference in behavioral ecology: some background, observations, and comparisons. Behav Ecol Sociobiol. 2010;65:23-35.

56. Grace JB, Schoolmaster DR Jr, Guntenspergen GR, Little AM, Mitchell BR, Miller KM, et al. Guidelines for a graph-theoretic implementation of structural equation modeling. Ecosphere. 2012;3:art73.

57. Borcard D, Legendre P, Drapeau P. Partialling out the spatial component of ecological variation. Ecology. 1992;73: 1045-55.

58. Breiman L. Random forests. Mach Learn. 2001;45:5-32.

59. Johnson JB, Omland KS. Model selection in ecology and evolution. Trends Ecol Evol. 2004;19:101-8.

60. Bartoń K. MuMIn: Multi-Model Inference. 2018.

61. Grace JB, Anderson TM, Seabloom EW, Borer ET, Adler PB, Harpole WS, et al. Integrative modelling reveals mechanisms linking productivity and plant species richness. Nature. 2016; 529:390.

62. Grace JB, Anderson TM, Olff H, Scheiner SM. On the specification of structural equation models for ecological systems. Ecol Monogr. 2010;80:67-87.

63. Rosseel Y. lavaan: an R package for structural equation modeling. J Stat Softw. 2012;48:1-36.

64. Li G, Xu G, Shen C, Tang Y, Zhang Y, Ma K. Contrasting elevational diversity patterns for soil bacteria between two ecosystems divided by the treeline. Sci China Life Sci. 2016;59: 1177-86.

65. Harsch MA, Hulme PE, McGlone MS, Duncan RP. Are treelines advancing? A global meta-analysis of treeline response to climate warming. Ecol Lett. 2009;12:1040-9.

66. Xu Z, Yang J, Hou Z, Zhang Z, Zeng L, Li H, et al. The progress in the study of continental dynamics of the Tibetan plateau. Geol China. 2016;43:1-42.

67. Searle MP, Roberts NMW, Chung S-L, Lee Y-H, Cook KL, Elliott JR, et al. Age and anatomy of the Gongga Shan batholith, eastern Tibetan Plateau, and its relationship to the active Xianshuihe fault. Geosphere. 2016;12:948-70.

68. Fierer N, Jackson RB. The diversity and biogeography of soil bacterial communities. Proc Natl Acad Sci USA. 2006;103: 626-31.

69. Garcia-Pichel F, Loza V, Marusenko Y, Mateo P, Potrafka RM. Temperature drives the continental-scale distribution of key microbes in topsoil communities. Science. 2013;340:1574-7.

70. Griffiths RI, Thomson BC, James P, Bell T, Bailey M, Whiteley AS. The bacterial biogeography of British soils. Environ Microbiol. 2011;13:1642-54.

71. Bahram M, Hildebrand F, Forslund SK, Anderson JL, Soudzilovskaia NA, Bodegom PM, et al. Structure and function of the global topsoil microbiome. Nature. 2018;560:233-7.

72. Zhou J, Deng Y, Shen L, Wen C, Yan Q, Ning D, et al. Temperature mediates continental-scale diversity of microbes in forest soils. Nat Commun. 2016;7:12083.

73. Delgado-Baquerizo M, Maestre FT, Reich PB, Jeffries TC, Gaitan JJ, Encinar D, et al. Microbial diversity drives multifunctionality in terrestrial ecosystems. Nat Commun. 2016;7:10541.

74. Jing X, Sanders NJ, Shi Y, Chu H, Classen AT, Zhao K, et al. The links between ecosystem multifunctionality and above- and belowground biodiversity are mediated by climate. Nat Commun. 2015;6:8159.

75. Wagg C, Bender SF, Widmer F, van der Heijden MGA. Soil biodiversity and soil community composition determine ecosystem multifunctionality. Proc Natl Acad Sci USA. 2014;111: $5266-70$. 
76. Louca S, Polz MF, Mazel F, Albright MBN, Huber JA, O’Connor $\mathrm{MI}$, et al. Function and functional redundancy in microbial systems. Nat Ecol Evolut. 2018;2:936-43.

77. Wagg C, Schlaeppi K, Banerjee S, Kuramae EE, van der Heijden MGA. Fungal-bacterial diversity and microbiome complexity predict ecosystem functioning. Nat Commun. 2019; 10:4841.

78. Craw D, Upton P, Burridge CP, Wallis GP, Waters JM. Rapid biological speciation driven by tectonic evolution in New Zealand. Nat Geosci. 2016;9:140-4.
79. Johnson JS, Krutovsky KV, Rajora OP, Gaddis KD, Cairns DM. Advancing biogeography through population genomics. In: Rajora O. (eds) Population Genomics. Population Genomics. Springer, Cham. 2018:p. 539-85.

80. Lu HP, Yeh YC, Sastri AR, Shiah FK, Gong GC, Hsieh CH. Evaluating community-environment relationships along fine to broad taxonomic resolutions reveals evolutionary forces underlying community assembly. ISME J. 2016;10:2867-78.

81. Zhang Z. Variable selection with stepwise and best subset approaches. Ann Transl Med. 2016;4:136.

\section{Affiliations}

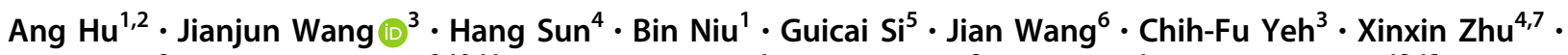 Xiancai Lu ${ }^{8}$ · Jizhong Zhou $\mathbb{D}^{9,10,11} \cdot$ Yongping Yang ${ }^{4} \cdot$ Minglei Ren ${ }^{3} \cdot$ Yilun Hu $\mathrm{Hu}^{1}$ Hailiang Dong ${ }^{12,13}$. Gengxin Zhang ${ }^{1}$}

1 Key Laboratory of Alpine Ecology and Biodiversity, Institute of Tibetan Plateau Research, Chinese Academy of Sciences, Beijing 100101, China

2 College of Resources and Environment, Hunan Agricultural University, Changsha 410128, China

3 State Key Laboratory of Lake Science and Environment, Nanjing Institute of Geography and Limnology, Chinese Academy of Sciences, Nanjing 210008, China

4 Kunming Institute of Botany, Chinese Academy of Sciences, Kunming 650204, China

5 Institute of Geology and Geophysics, Chinese Academy of Sciences, Lanzhou 730000, China

6 Land and Resource College, China West Normal University, Nanchong 637009, China

7 Life Sciences College, Xinyang Normal University, Xinyang 464000, China
8 China State Key Laboratory for Mineral Deposits Research, School of Earth Sciences and Engineering, Nanjing University, Nanjing 210093, China

9 Department of Microbiology and Plant Biology, Institute for Environmental Genomics, University of Oklahoma, Norman, OK 73019, USA

10 State Key Joint Laboratory of Environment Simulation and Pollution Control, School of Environment, Tsinghua University, Beijing 100084, China

11 Earth Science Division, Lawrence Berkeley National Laboratory, Berkeley, CA 94270, USA

12 Department of Geology and Environmental Earth Science, Miami University, Oxford, OH 45056, USA

13 State Key Laboratory of Biogeology and Environmental Geology, China University of Geosciences, Beijing 100083, China 